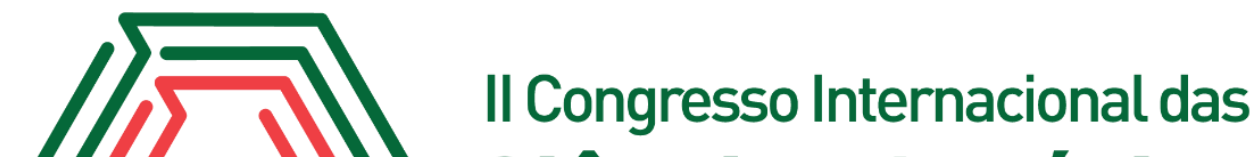 Ciências Agrárias COINTER - PDVAgro 2017
}

\section{EFEITO DA RECUPERAÇÃO DE GORDURA E CASEÍNA NO SORO SOBRE O RENDIMENTO DE QUEIJO MOZZARELLA OBTIDO A PARTIR DO LEITE BUBALINO}

Apresentação: Pôster

Danielle Cavalcanti Sales ${ }^{1}$; Joadilza da Silva Bezerra ${ }^{2}$; Yhêlda Maria de Oliveira Silva ${ }^{3}$; Humberto Tonhati ${ }^{4}$; Adriano Henrique do Nascimento Rangel ${ }^{5}$

\section{Introdução}

A Mozzarella é um queijo típico da Itália, consumido em todo o mundo e produzido em algumas indústrias brasileiras seguindo o modo italiano. Estudos no contexto da fabricação da Mozzarella e da eficiência de uso de sua matéria prima (leite bubalino) ainda são restritos no meio científico, principalmente no Brasil.

A busca por um crescimento favorável à indústria láctea implica na necessidade de execução eficiente dos processos produtivos, com alto rendimento de fabricação, máximo aproveitamento dos sólidos da matéria-prima, e mínimo volume de efluente (soro). A caseína e a gordura são os dois elementos essenciais para obtenção de queijos. Eles constituem a estrutura física da coalhada e, por isso, o seu aproveitamento pode influenciar o rendimento de queijos.

O presente estudo parte da hipótese de que a perda de gordura e caseína através do soro tenha efeito negativo sobre o rendimento na fabricação de Mozzarella a partir do leite bubalino. Objetivou-se avaliar o efeito da recuperação de gordura e caseína no soro sobre o rendimento de queijo Mozzarella obtido de leite bubalino. Espera-se contribuir para a comunidade científica a cerca da relação entre a perda de constituintes e o rendimento industrial durante o processo de fabricação de Mozzarella.

\footnotetext{
${ }^{1}$ Curso de Doutorado, Universidade Estadual Paulista Júlio de Mesquita Filho, UNESP, daniellecsales@hotmail.com

${ }^{2}$ Curso de Mestrado, Programa de Pós-graduação em Produção Animal, PPGPA, Universidade Federal do Rio Grande do Norte, UFRN, Campus Macaíba, joabezarra@yahoo.com.br

${ }^{3}$ Curso de Zootecnia, UFRN, yhelda maria @hotmail.com

${ }^{4}$ Professor, Universidade Estadual Paulista Júlio de Mesquita Filho, UNESP, tonhati@fcav.unesp.br

${ }^{5}$ Professor, Universidade Federal do Rio Grande do Norte, UFRN, adrianohrangel@yahoo.com.br
} 


\section{Fundamentação Teórica}

O queijo Mozzarella é um produto típico da Itália, e tem sua fabricação relativamente recente no Brasil, onde se emprega um processamento similar ao italiano e usando necessariamente o leite bubalino integral (ABCB, 2014).

Apesar de tantos fatores estarem envolvidos com a fabricação do queijo e sua eficiência, como o processo ocorre através da concentração dos sólidos do leite na massa (coalhada), o rendimento tem uma relação muito íntima com a composição da matéria prima. Durante a coagulação, a caseína se organiza como uma rede e entrelaça a gordura, fato essencial para a obtenção do queijo ao final do processo (GARCIA et al., 2008; SALES et al., 2017). Desta forma, a caseína é o componente do leite que tem maior relação funcional com a massa do queijo, seguido da gordura e, por isso, elas são os componentes do leite mais importantes sob o ponto de vista industrial.

O rendimento na fabricação de derivados lácteos pode dar indícios do sucesso produtivo e é uma ferramenta valiosa para o aperfeiçoamento do processo e para o equilíbrio custo-lucro da empresa. Inúmeros fatores têm efeito sobre o rendimento de derivados lácteos, que podem ser ligados diretamente aos animais, como genética, alimentação, estado fisiológico e sanidade; ou ligados à manipulação e aproveitamento da matéria-prima, como as técnicas empregadas no processamento e as perdas de constituintes através do soro (TRIPALDI ET AL, 2003; ABD ELGAWAD AND AHMED, 2011).

O rendimento de queijo representa a relação entre o volume de leite empregado e de queijo produzido em um laticínio. De modo complementar, a recuperação de sólidos no soro indica o percentual de sólidos do leite perdidos como resíduo do processo (PERRONE et al., 2010). Tanto o rendimento quanto a recuperação de constituintes no soro do queijo são ferramentas válidas para que a indústria detenha de informações acerca do aproveitamento de sua matéria prima para melhor gestão produtiva (SALES et al., 2017).

\section{Metodologia}

A pesquisa tem natureza quantitativa do tipo experimental. $\mathrm{O}$ estudo foi realizado em um laticínio situado no município de Taipu/RN. Foi acompanhada a fabricação de 27 lotes de queijo Mozzarella (bola) obtido a partir da coagulação enzimática de leite bubalino, seguindo etapas 
descritas por Sales et al. (2017a).

Para cada lote foi retirada uma amostra de leite cru antes do processamento, e foram registrados o volume de leite usado e a massa de queijo produzida. As amostras de leite destinadas à análise físico-química foram coletadas no fluxo de sua chegada ao laticínio, antes da pasteurização. Elas foram acondicionadas em frascos plásticos com capacidade de $40 \mathrm{~mL}$, identificadas e transportadas sob temperatura entre 3 e $5^{\circ} \mathrm{C}$ até o Laboratório de Qualidade do Leite da Universidade Federal do Rio Grande do Norte (LABOLEITE). O percentual de gordura e caseína do leite e do soro foi determinado através de absorção infravermelha no Bentley $2000^{\circledR}$ (Bentley Instruments Inc., Chasca MN, EUA).

O volume exato de leite empregado no processo (VL) foi obtido a partir do cálculo da área ocupada no tanque, através da equação $\mathrm{VL}=\mathrm{A} \times \mathrm{L} \times \mathrm{C}$, em que: $\mathrm{A}=$ altura atingida pela lâmina de leite, em relação à parede do tanque $(\mathrm{cm}) ; \mathrm{L}=$ largura do tanque de produção $(\mathrm{cm}) ; \mathrm{C}=$ comprimento do tanque de produção $(\mathrm{cm})$. O volume de leite, em litros, foi convertido para quilogramas através do produto entre VL e a densidade do leite $(\mathrm{kg} / \mathrm{L})$. O rendimento da Mozzarella (RM) foi obtido através da razão entre VL $(\mathrm{kg})$, em quilogramas pela massa de queijo produzido (MQ), em quilogramas.

A recuperação (RES) de gordura e caseína no soro foi obtida pela razão entre o teor do componente no soro $(\%)$ pelo teor do mesmo componente no leite $(\%)$, como proposto por Furtado e Pombo (1979).

Os dados foram submetidos à análise de variância e de regressão polinomial adotando-se 5\% de probabilidade, por meio do programa estatístico R, versão 3.4.0.

\section{Resultados e Discussões}

A Tabela 1 apresenta as equações com coeficientes de regressão, p-valor, coeficiente de determinação $\left(\mathrm{R}^{2}\right)$ e critério de informação Akaike (AIC) para o rendimento de Mozarella. Houve influencia significativa da recuperação de gordura $(R G)$ e de caseína $(R C)$ sobre o rendimento $(p<0,05)$ (Tabela 1). $\mathrm{O}$ comportamento do rendimento em relação à $\mathrm{RG}$ segue uma curva de tendência baseada no modelo de regressão cúbico (Figura 1). Já em relação à RC, o rendimento tem comportamento linear (Figura 2).

De fato, a caseína, porção proteica de maior propriedade tecnológica para o fabrico de 
queijos, está associada à coagulação do leite, à retenção dos constituintes na massa e ao rendimento do queijo. Cecchinato e Bittante (2016) através de um estudo detalhado sobre a relação entre as propriedades de coagulação do leite, a recuperação de constituintes e o rendimento de queijo, demonstraram que a recuperação de proteína se relaciona fortemente com o rendimento, demonstrando ser um elemento importante a ser considerado quando se pretende aumentar a eficiência de fabricação de queijo.

Tabela 1. Efeito da recuperação de gordura (RG) e caseína (RC) no soro sobre o rendimento de Mozzarella obtida a partir de leite bubalino. Fonte: própria.

\begin{tabular}{lllll}
\hline Variáveis, unidade & Equações de regressão & P-valor & R $^{2}$ & AIC \\
\hline $\mathrm{RG}, \%$ & $\hat{\mathrm{y}}=-10,632+9,597 \mathrm{RG}-1,878 \mathrm{RG}^{2}+0,117 \mathrm{RG}^{3}$ & 0,015 & 0,4334 & 12,16 \\
$\mathrm{RC}, \%$ & $\hat{\mathrm{y}}=10,126-0,152 \mathrm{RC}$ & 0,049 & 0,1889 & 16,84 \\
\hline
\end{tabular}

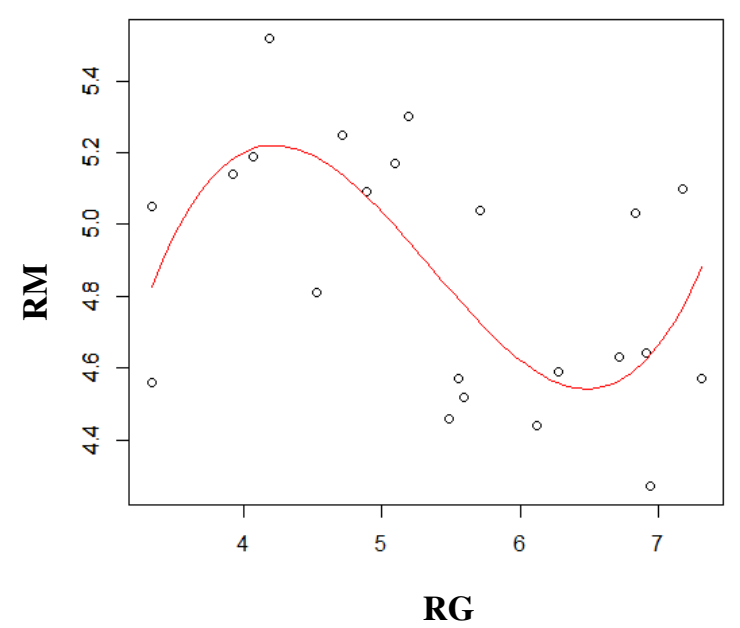

Figura 1. Comportamento do rendimento de Mozzarella $(\mathrm{RM})$ em relação à recuperação de gordura $(\mathrm{RG})$ no soro $(\hat{y}=-$ $\left.10,632+9,597 R G-1,878 R G^{2}+0,117 R G^{3} ; \mathrm{R}^{2}=0,4334 ; \mathrm{AIC}=12,16\right)$. Fonte: própria.

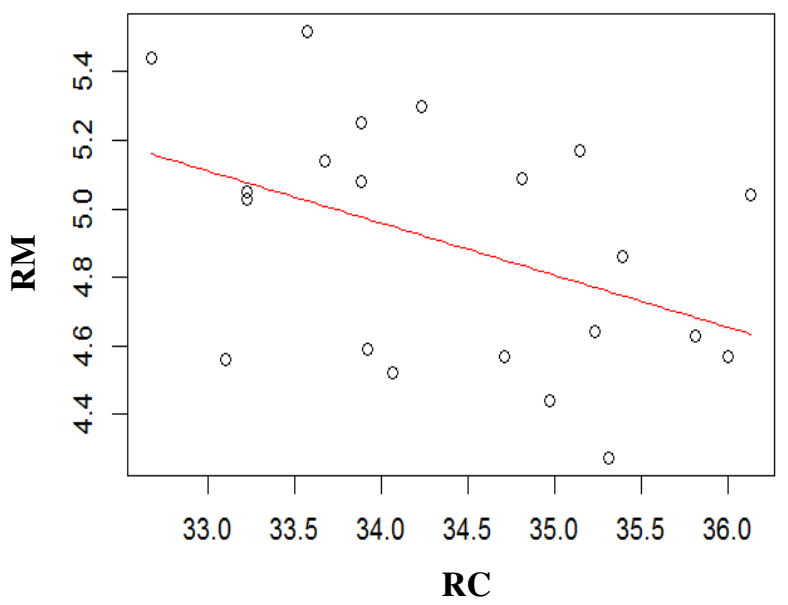

Figura 1. Comportamento do rendimento de Mozzarella $(\mathrm{RM})$ em relação à recuperação de caseína $(\mathrm{RC})$ no soro $\left(\hat{y}=10,126-0,152 R C ; \mathrm{R}^{2}=0,1889 ; \mathrm{AIC}=16,84\right)$. Fonte: própria. 
Boa parte da gordura do leite normalmente participa na constituição da Mozzarella, uma vez que sua perda atinge menos de $6 \%$ no soro (Sales et al., 2017b). Entretanto, o leite ou a massa do queijo podem sofrer perdas significativas de gordura ainda durante o processamento. Para Cecchinato e Bittante (2016), as variações na recuperação de gordura têm muito a ver com o tempo de coagulação do leite (firmeza da coalhada $\mathrm{x}$ tempo), principalmente durante a ultima fase de endurecimento (cerca de 45 minutos após a adição do coalho) da mesma.

Não há prejuízo significativo ao rendimento quando se produz queijo a partir de maiores concentrações de caseína, mesmo que haja aproveitamento baixo de gordura na coalhada (e muita perda no soro) (Sales et al., 2017b). Isso pode ser explicado pelo fato de a caseína ser elementar na estruturação da coalhada e retenção de outros constituintes, o que pode compensar as perdas de gordura.

\section{Conclusões}

Como o queijo tem maior valor agregado em relação ao do próprio leite, o ideal é que se aproveite o máximo possível dos componentes lácteos. Conhecendo e controlando a recuperação dos constituintes no soro e o rendimento de fabricação, o laticínio consegue gerir melhor a sua eficiência e padronizar as características físico-químicas e organolépticas do queijo Mozzarella, garantindo uma estabilidade na qualidade para o consumidor.

\section{Referências}

BASTOS, P. A. S. BIRGEL, E. H. Leite de búfalas Murrah criadas em São Paulo (Brasil): influência da idade, fase de lactação, momento da ordenha e isolamento bacteriano na composição físico-química e celular. Revista de Educação Continuada em Medicina Veterinária e Zootecnia. v. 9, n. 3, p. 06-13, 2011.

CECCHINATO, A; BITTANTE, G. Genetic and environmental relationships of different measures of individual cheese yield and curd nutrients recovery with coagulation properties of bovine milk. Journal of Dairy Science, v. 99, p.1975-1989, 2016.

SALES, D.C. et al. Buffalo milk composition, processing factors, whey constituents recovery and yield in manufacturing Mozzarella cheese. Food Sci. Technol, Campinas, Epub Sep 04, 2017a. http://dx.doi.org/10.1590/1678-457x.04317.

SALES, D.C. et al. Relationship between mozzarella yield and milk composition, processing factors, 
and recovery of whey constituents. Journal of Dairy Science, v. 100, p. 4308-4321, 2017 b. http://dx.doi.org/10.3168/jds.2016-12392. 